\title{
Central nervous system-impairing effects of hydroxyzine as a function of histamine availability
}

Citation for published version (APA):

Conen, S., Theunissen, E. L., Vermeeren, A., Sambeth, A., \& Ramaekers, J. G. (2013). Central nervous system-impairing effects of hydroxyzine as a function of histamine availability. Journal of Clinical Psychopharmacology, 33(2), 276-279. https://doi.org/10.1097/JCP.0b013e31828052ac

Document status and date:

Published: 01/04/2013

DOI:

10.1097/JCP.0b013e31828052ac

Document Version:

Publisher's PDF, also known as Version of record

Document license:

Taverne

Please check the document version of this publication:

- A submitted manuscript is the version of the article upon submission and before peer-review. There can be important differences between the submitted version and the official published version of record.

People interested in the research are advised to contact the author for the final version of the publication, or visit the DOI to the publisher's website.

- The final author version and the galley proof are versions of the publication after peer review.

- The final published version features the final layout of the paper including the volume, issue and page numbers.

Link to publication

\footnotetext{
General rights rights.

- You may freely distribute the URL identifying the publication in the public portal. please follow below link for the End User Agreement:

www.umlib.nl/taverne-license

Take down policy

If you believe that this document breaches copyright please contact us at:

repository@maastrichtuniversity.nl

providing details and we will investigate your claim.
}

Copyright and moral rights for the publications made accessible in the public portal are retained by the authors and/or other copyright owners and it is a condition of accessing publications that users recognise and abide by the legal requirements associated with these

- Users may download and print one copy of any publication from the public portal for the purpose of private study or research.

- You may not further distribute the material or use it for any profit-making activity or commercial gain

If the publication is distributed under the terms of Article $25 \mathrm{fa}$ of the Dutch Copyright Act, indicated by the "Taverne" license above, 
have a stable partner and was compulsive at the most distant time period from the ovulation.

There are no clear recommendations for the treatment of SA. ${ }^{1}$ Different types of psychotherapy have been proposed, but none has demonstrated efficacy in a controlled trial. Psychopharmacologic agents used for the treatment of the paraphilias could also provide a basis for treatment of SA because both types of disorders often involve sexual behavior that is out of control. ${ }^{2}$ Best evidence is found for SSRIs and antiandrogen treatment. ${ }^{1}$

Cyproterone treatment is registered in more than 20 countries for male paraphilia. It is also widely used for acne and feminine hirsutism. Loss of libido is a frequent adverse effect of cyproterone treatment in hirsute women. ${ }^{15}$ Two other cases of cyproterone treatment of female hypersexuality have been published. Mellor et al ${ }^{16}$ treated a 40-year-old woman who sexually assaulted a man in spite of many years of psychiatric treatments for hypersexuality. Eriksson ${ }^{17}$ treated a 49 -year-old woman with history of persistent obsessive sexual thoughts. After 3 days of cyproterone $100 \mathrm{mg} / \mathrm{d}$, all the symptoms had disappeared. Treatment was prolonged for 2 years without relapse. Our case differs from those already reported because our patient presented episodic SA that is exceptionally reported. Rapid efficacy was observed in all published cases, including our. Depressed mood is a frequent reported adverse effect of cyproterone. ${ }^{5}$ Miss $\mathrm{Z}$ did not report increased depression with this prescription. However, a close monitoring may be indicated when initiating such treatment to patients with a mood disorder.

Our case report suggests that disorders of sexual regulation may also be episodic and not only persisting. It also supports the efficacy of cyproterone, a treatment widely used in women for other conditions. Other case reports and specific surveys are needed to further explore the different syndromes of SA, especially in women. Controlled trials are needed for this disorder that may be concealed but results in serious social damage for sufferers.

\section{ACKNOWLEDGMENT}

The authors thank the patient for giving written permission to publish this case report.

\section{AUTHOR DISCLOSURE INFORMATION}

The authors declare no conflicts of interest.
Roland Dardennes, MD, MS

Faculty of Medicine

Paris Descartes University

and Centre Hospitalier Sainte-Anne

Clinique des maladies mentales et de l'encéphale (CMME)

and Center of Psychiatry and Neuroscience Sainte-Anne Hospital Inserm U894 Paris, France

r.dardennes@ch-sainte-anne.fr

Nebal Al Anbar, PhD

Center of Psychiatry and Neuroscience Sainte-Anne Hospital Inserm U894

and Pierre et Marie Curie University

Doctoral School 158

"Brain-Cognition-Behaviour" Paris, France

Frédéric Rouillon, MD Faculty of Medicine Paris Descartes University and Centre Hospitalier Sainte-Anne Clinique des maladies mentales et de l'encéphale (CMME) and Center of Psychiatry and Neuroscience Sainte-Anne Hospital Inserm U894 Paris, France

\section{REFERENCES}

1. Garcia FD, Thibaut F. Sexual addictions. Am J Drug Alcohol Abuse. 2010;36:254-260.

2. Kaplan MS, Krueger RB. Diagnosis, assessment, and treatment of hypersexuality. J Sex Res. 2010;47:181-198.

3. Orford J. Hypersexuality: implications for a theory of dependence. $\mathrm{Br} J \mathrm{Add}$. 1978;73:299-310.

4. Coleman E, Raymond N, McBean A. Assessment and treatment of compulsive sexual behaviour. Minn Med. 2003;86:42-47.

5. Guay DR. Drug treatment of paraphilic and nonparaphilic sexual disorders. Clin Ther. 2009;31:1-31.

6. Kalichman SC, Rompa D. Sexual sensation seeking and Sexual Compulsivity Scales: reliability, validity, and predicting HIV risk behavior. $J$ Pers Assess. 1995;65:586-601.

7. Grabowska-Grzyb A, Nagańska E, Wolańczyk T. Hypersexuality in two patients with epilepsy treated with lamotrigine. Epilepsy Behav. 2006;8:663-665.

8. Greil W, Horvath A, Sassim N, et al. Disinhibition of libido: an adverse effect of SSRI? J Affect Disord. 2001;62: 225-228.

9. Jefferson JW, Greist JH, Ackerman DL, et al. Lithium Encyclopedia for Clinical Practice. 2nd ed. Washington, DC: American Psychiatric Press, Inc.; 1987.
10. Judd LL, Akiskal HS. The prevalence and disability of bipolar spectrum disorders in the US population: re-analysis of the ECA database taking into account subthreshold cases. J Affect Disord. 2003;73:123-131.

11. Arnulf I, Zeitzer JM, File J, et al. Kleine-Levin syndrome: a systematic review of 186 cases in the literature. Brain. 2005;128:2763-2776.

12. Basson R, Leiblum S, Brotto L, et al. Definitions of women's sexual dysfunction reconsidered: advocating expansion and revision. J Psychosom Obstet Gynaecol. 2003;24:221-229.

13. Gondim FA, Thomas FP. Episodic hyperlibidinism in multiple sclerosis. Mult Scler. 2001;7:67-70.

14. Pillsworth EG, Haselton MG, Buss DM. Ovulatory shifts in female sexual desire. $J$ Sex Res. 2004;41:55-65.

15. Appelt H, Strauss B. Effects of antiandrogen treatment on the sexuality of women with hyperandrogenism. Psychother Psychosom. 1984;42:177-181.

16. Mellor CS, Farid NR, Craig DF. Female hypersexuality treated with cyproterone acetate. Am J Psychiatry. 1988;145:1037.

17. Eriksson T. Anti-androgenic agent cyproterone acetate cured a woman of severe sexual obsessions. Br J Psychiatry. 1998; $173: 351$.

\section{Central Nervous} System-Impairing Effects of Hydroxyzine as a Function of Histamine Availability

\section{To the Editors:}

I a recent study we published in this journal, ${ }^{1}$ it was hypothesized that the sedative antihistaminergic effects of firstgeneration antihistamine hydroxyzine would be maximal in the evening when histamine levels are low and less in the morning when histamine levels are high, as a result of increased competition between histamine and hydroxyzine in the central nervous system in the morning. However, the results of the behavioral data were opposite to the hypothesis. In the evening, the sedative effects were only apparent in parts of 2 attention tasks; whereas in the morning, hydroxyzine impairment was very prevalent in most of the performance outcomes. Moreover, performance impairments observed after a morning dose were significantly larger than those observed after an evening dose of hydroxyzine for several tasks. For the specific procedure and detailed description of tests, as well as the results of the behavioral data, we refer to our previous 
publication. ${ }^{1}$ The present report focuses on the results from event-related potentials (ERPs) measured in the same study.

For the ERPs, it was also expected that sedative effects of hydroxyzine would be apparent in the evening, in the form of delayed peak latencies and decreased peak amplitudes, compared to placebo Event-related potentials were measured in the context of a divided attention task $\left(\mathrm{DAT}^{2}\right)$ and an attention network task (ANT). The DAT measures the ability to perform 2 tasks simultaneously. Participants have to divide their attention between the primary task of tracking performance and a secondary task that consists of monitoring a sequence of digits (ranging from 0 to 9 ) in the middle of the screen. Event-related potentials were measured and averaged in relation to the secondary task in which subjects had to respond to the digit " 2 " (ie, the target). The ANT measures reaction times to warning cues, spatial orienting cues and flankers, and is used to assess 3 separate aspects of the attentional network: alerting, orienting, and executive control. ${ }^{3}$ Efficiency of these networks was measured by ERP changes in latency and amplitude between: (1) center cues and no cues for the alerting network; (2) center cues and spatial cues for the orienting network; and (3) incongruent and congruent flankers for the executive network.

Electroencephalographic (EEG) activity was recorded from 32 electrodes
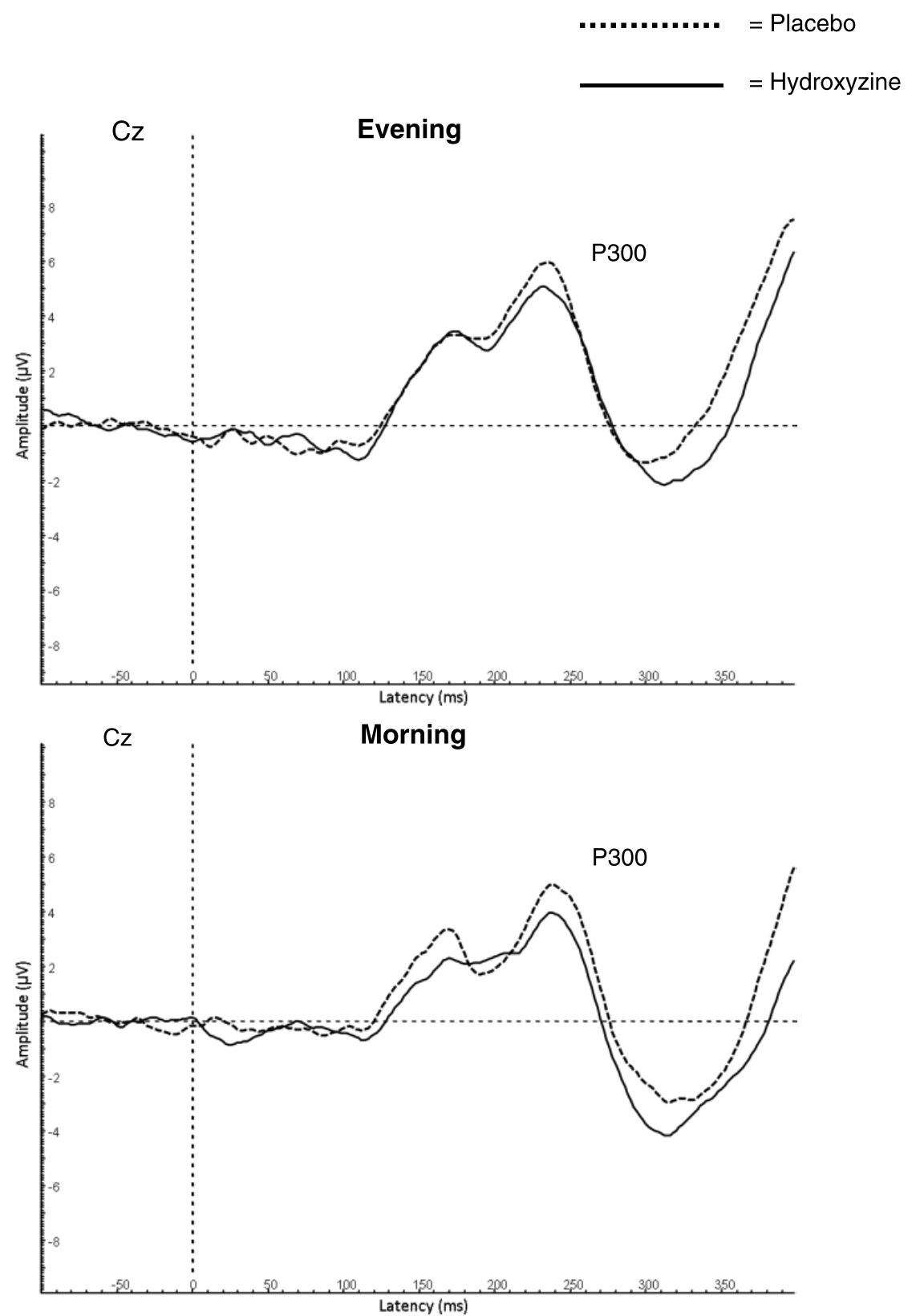

FIGURE 1. Grand average ERPs at Cz of the DAT. P300 latencies are shown on the $x$-axis in milliseconds, and amplitudes are presented on the $y$-axis in microvolts. In the morning, target amplitude was significantly decreased after hydroxyzine treatment. 
according to the international 10-20 system, ${ }^{4}$ using Neuroscan software. All electrode impedances were kept below $5 \Omega$. All signals were sampled at a $500-\mathrm{Hz}$ frequency and filtered online using a 250-Hz low-pass filter and a 0.05-high-pass filter. All sampled EEG and electrooculography epochs were filtered off-line using a $30-\mathrm{Hz}$ filter. Electroencephalograms were corrected for vertical and horizontal eye movements according to Gratton and Coles method. ${ }^{5}$ The EEG fragments within an epoch of 100 milliseconds (ms) before target stimulus onset and $1000 \mathrm{~ms}$ after onset were averaged using the prestimulus interval as baseline. The EEG fragments were averaged for each treatment separately.

Using former studies as reference, ${ }^{2,3}$ the ERP components of interest in the present tasks were P100, N100, N200, and P300. Both N100 and P100 are early sensory-evoked components that are larger in response to attended than unattended stimuli, ${ }^{6,7}$ Higher-level components N200 and P300 were also measured. N200 reflects attention switching processes ${ }^{8}$ and is affected by conflict trials. ${ }^{9}$ Parietal P300 is believed to reveal neural inhibition of current activity to facilitate transmission of stimulus/task information and is therefore related to processing of incoming information. ${ }^{10}$

For both tasks, ERPs were analyzed at $\mathrm{Fz}, \mathrm{FCz}, \mathrm{Cz}, \mathrm{Pz}, \mathrm{P} 3$, and $\mathrm{P} 4$ electrode positions. The P100 component was established as the highest amplitude within a time window of 50 to $160 \mathrm{~ms}$ after stimulus onset, and N100 as the lowest amplitude within 80-180 ms. N200 was determined as the lowest amplitude within a time window of 180 to $300 \mathrm{~ms}$ and the P300 component as the highest amplitude within 220 to $320 \mathrm{~ms}$ after stimulus onset. All the time windows were defined after inspection of the grand averages. Additionally, the latencies of these 4 peaks were included in the analysis. The ERP data were analyzed by means of paired-samples $t$ tests. The effects of hydroxyzine in the evening were compared with the effects of placebo in the evening, and the effects of hydroxyzine in the morning were compared with the effects of placebo in the morning.

The results of the ERPs in the DAT showed that overall, more impairing effects of hydroxyzine were apparent in the morning, as N100 latency was increased at $\mathrm{Cz}\left(t_{15}=2.5 ; P=0.03\right)$, and $\mathrm{P} 300 \mathrm{am}-$ plitude was decreased at $\mathrm{Cz}\left(t_{15}=-2.8\right.$; $P=0.015), \mathrm{Pz}\left(t_{15}=-2.1 ; P=0.05\right), \mathrm{P} 3$ $\left(\mathrm{t}_{15}=2.6 ; P=0.018\right)$, and $\mathrm{P} 4\left(t_{15}=-2.2\right.$; $P=0.042)$. In the evening, less impairing effects were apparent as P100 amplitude was significantly decreased after hydroxyzine at $\mathrm{Fz}\left(t_{15}=2.6 ; P=0.013\right)$, whereas $\mathrm{N} 200$ and $\mathrm{P} 300$ latency were increased at $\mathrm{Cz}\left(t_{15}=2.6 ; P=0.021\right)$ and $\mathrm{Pz}\left(\mathrm{t}_{15}=2.6\right.$, $P=0.02)$, respectively. To summarize, the relationship between hydroxyzine treatment and P300 at $\mathrm{Cz}$ is plotted in Figure 1.

The results of the ERPs in the ANT showed that in the morning, a decreased alerting effect in N200 amplitude was apparent at $\mathrm{Cz}$ after hydroxyzine $\left(t_{15}=-2.37\right.$; $P<0.03)$. For the other attention networks, no significant treatment effects were present for ERP latency or amplitude in the ANT. In the evening, significant differences in alerting effects (no cue minus center cue conditions) were present as indicated by an increase in P300 latency at P3 $\left(t_{15}=3.25\right.$; $P=0.005)$ after hydroxyzine. Significant orienting effects (center cue minus spatial cue) were present in the evening as indicated by an increase in P300 latency at $\mathrm{Cz}$ $\left(t_{15}=3.89 ; P=0.001\right)$ and a decrease in P300 amplitude at P3 $\left(t_{15}=-2.46 ; P=\right.$ $0.027)$ after hydroxyzine treatment. No treatment effects were present for the conflict effect (incongruent minus congruent flankers).

Event-related potential data of the DAT confirmed previous behavioral data, ${ }^{1}$ which demonstrated that hydroxyzine effects on divided attention task performance were worse in the morning compared to the evening. Hydroxyzine did affect ERPs aspecifically, but the effects were mostly apparent at the P300 component. Latencies increased and amplitudes decreased after hydroxyzine on several electrode positions, showing that sedation was more apparent in the morning instead of the evening for the targets. As the P300 component has been linked to facilitating the transmission of stimulus/task information, ${ }^{10}$ it can be concluded that this facilitation was inhibited after hydroxyzine treatment, with more effects in the morning condition.

The ERP data of the ANT demonstrated that both the alerting and orienting network were significantly affected by hydroxyzine. During the hydroxyzine treatment, the subjects were less alert (ie, less benefit from a warning cue) both in the evening and in the morning. P300 amplitude during orienting tasks was mostly affected in the evening, indicating that subjects had less benefit from a spatial cue after hydroxyzine. P300 latency at $\mathrm{Cz}$ was also affected by hydroxyzine during orienting, but here, participants apparently had more benefit from a spatial cue in the hydroxyzine condition. As the effects were more prominent in the evening, the ERP data from the ANT seems to confirm our original hypothesis. However, ERP data were not in line with the behavioral data of the ANT that we have presented before. These performance data showed that hydroxyzine impairment was apparent both in the evening and in the morning, and only during conflict tasks. The apparent conflicts between behavioral data and ERP data in the ANT tasks and between ERP latency and amplitude during orienting therefore indicate that the present ERP results of the ANT should be interpreted with caution.

A number of reasons may have accounted for the finding that hydroxyzine effects were generally worse after morning doses compared to evening doses. First, the actual brain histamine levels during testing in the evening and morning are unknown and, as a consequence, the timing of hydroxyzine intake may have been incorrect. Second, a larger impairment in the morning dose condition compared with the evening dose condition could also be explained by sleep inertia, ${ }^{11}$ as this may interact with the sedative effects of hydroxyzine to increase impairing effects on performance. Third, variations in pharmacokinetics during the day may have affected the pharmacodynamics of hydroxyzine. ${ }^{12}$ It is possible that hydroxyzine might be absorbed faster in the morning, which can lead to a higher $C_{\max }$, which could partially contribute to differences in hydroxyzine effects observed in the present study.

In summary, although the ANT ERP data are in line with our hypotheses, these data should be interpreted with caution because the number of effects were limited and in contrast with hydroxyzine effects on behavioral parameters of the ANT. Event-related potential data of the DAT indicate that hydroxyzine-induced impairment was more prominent after morning doses compared to evening doses and supports previous behavioral data. Therefore, the present study could not provide unambiguous evidence to confirm the hypothesis that histamine availability inversely affects magnitude of antihistamine impairment.

\section{ACKNOWLEDGMENTS}

The authors thank Cees van Leeuwen for the medical supervision; Fren Smulders for advice concerning the ERP measurements; Jin Fan for the opportunity of using the attention network test; and Natalie Valle Y Guzman, Lieke Heil, and Eva Drexler for their assistance in data collection.

\section{AUTHOR DISCLOSURE INFORMATION}

The authors declare no conflicts of interest. 
This trial has been registered at www. trialregister.nl as NTR1816 http://www. trialregister.nl/trialreg/admin/rctview. asp? $T C=1816$.

Silke Conen, PhD

Department of Neuropsychology and Psychopharmacology

Faculty of Psychology and Neuroscience Maastricht University The Netherlands

Current address: Neuroscience and Psychiatry Unit

Institute of Brain, Behaviour and Mental Health University of Manchester United Kingdom silke.conen@manchester.ac.uk

Eef L. Theunissen, PhD Annemiek Vermeeren, PhD Anke Sambeth, PhD Johannes G. Ramaekers, PhD Department of Neuropsychology and Psychopharmacology

Faculty of Psychology and Neuroscience Maastricht University The Netherlands

\section{REFERENCES}

1. Conen S, Theunissen EL, Vermeeren A, et al Short-term effects of morning versus evening dose of hydroxyzine $50 \mathrm{mg}$ on cognition in healthy volunteers. J Clin Psychopharmacol. 2011;31(3):294-301.

2. Theunissen EL, Jonkman LM, Kuypers KP, et al. A combined neurophysiological and behavioural study into the stimulating effects of fexofenadine on performance. $J$ Psychopharmacol. 2006;20(4):496-505.

3. Fan J, Byrne J, Worden MS, et al. The relation of brain oscillations to attentional networks. J Neurosci. 2007;27(23):6197-6206.

4. Jasper HH. The ten-twenty electrode system of the international federation. Electroencephalogr Clin Neurophysiol. 1958;10:371-375.

5. Gratton G, Coles MG, Donchin E. A new method for off-line removal of ocular artifact Electroencephalogr Clin Neurophysiol. 1983;55(4):468-484.

6. Golob EJ, Pratt H, Starr A. Preparatory slow potentials and event-related potentials in an auditory cued attention task. Clin Neurophysiol. 2002;113(10):1544-1557.

7. Mangun GR. Neural mechanisms of visual selective attention. Psychophysiology. 1995;32(1):4-18.

8. Kasai K, Nakagome K, Hiramatsu K, et al. Psychophysiological index during auditory selective attention correlates with visual continuous performance test sensitivity in normal adults. Int J Psychophysiol. 2002;45(3):211-225.

9. van Veen V, Carter CS. The anterior cingulate as a conflict monitor: fMRI and ERP studies. Physiol Behav. 2002;77(4-5):477-482.
10. Polich J. Updating P300: an integrative theory of P3a and P3b. Clin Neurophysiol. 2007;118(10):2128-2148

11. Tassi P, Muzet A. Sleep inertia. Sleep Med Rev. 2000;4(4):341-353.

12. Baraldo $M$. The influence of circadian rhythms on the kinetics of drugs in humans. Expert Opin Drug Metab Toxicol. 2008;4(2):175-192.

\section{Glycopyrrolate for Antidepressant-Associated Excessive Sweating}

\section{To the Editors:}

Antidepressant-associated excessive sweat$A$ ing occurs in $5 \%$ to $14 \%$ of patients on an antidepressant (www.pdr.net) and with almost all available antidepressants. It can cause significant distress, functional impairment, and nonadherence to the antidepressant. ${ }^{1}$ This adverse effect may continue even after several months on the antidepressant, ${ }^{2}$ but tends to be under-recognized.

In some patients, continuing the offending antidepressant at the same dose is clinically essential and discontinuing or changing the antidepressant, or reduction in dose, are either not feasible or do not work. In such patients, a medication to treat the excessive sweating can be very valuable. Sweat glands are innervated with cholinergic nerve endings and case reports have suggested the potential efficacy of anticholinergics for the excessive sweating (eg, benztropine ${ }^{3,4}$ and oxybutynin ${ }^{5}$ ).

However, medications like benztropine readily cross the blood-brain barrier and tend to cause cognitive adverse effects. Glycopyrrolate is an anticholinergic that does not cross the blood-brain barrier to a great extent and is therefore preferentially used in several clinical situations, especially as an adjunct to anesthesia. Although it may be associated with any of the adverse effects of anticholinergics, it is significantly less likely to cause central adverse effects. ${ }^{6}$ A case series has described its efficacy for localized and generalized hyperhidrosis. ${ }^{7}$ Here, we report its successful use for the treatment of antidepressant-associated excessive sweating.

\section{CASE REPORT}

Ms A was a 28-year-old woman who was being treated for a depressive disorder with duloxetine $60 \mathrm{mg} / \mathrm{d}$ and lorazepam $1 \mathrm{mg} / \mathrm{d}$. Starting soon after being put on duloxetine, Ms A began to sweat excessively. Although her workplace was air-conditioned and the temperature was kept quite low, her face and chest would sometimes suddenly start to sweat. The sweating would last for approximately 5 minutes at a time. She stopped wearing makeup because the sweat would make it run. The armpits, palms, and legs were largely spared from the sweating. At night, she would wake up and find her T-shirt soaked with sweat, although her boyfriend was not too warm. She stopped wearing sweaters because now they made her feel too warm. She began to dress in layers so that she could remove some outer layers when needed. Interaction with others made her more aware of, and more distressed by, the excessive sweating. She felt embarrassed because her face would often start to sweat while she was speaking and she had to wipe her face during the conversation.

Ms A had a normal thyroid-stimulating hormone level. Because she had tried several antidepressants before finding the duloxetine that was substantially helpful to her, she declined to change the antidepressant or reduce the dose. She was put on glycopyrrolate $0.5 \mathrm{mg}$ BID and gradually increased to $1 \mathrm{mg}$ TID. The excessive sweating resolved completely within a couple of weeks although this was in June and the weather was hot. There were no adverse effects and she remained free of depression. The excessive sweating did not return even when later she was diagnosed as adult attention deficit hyperactivity disorder and treated with mixed amphetamine salts. However, when she ran out of the glycopyrrolate and missed it for a week, marked sweating promptly returned. Later, she was tapered off the duloxetine due to planning a pregnancy and was then able to stop the glycopyrrolate without return of excessive sweating.

MEDLINE and Scopus were searched using the MeSH terms "antidepressive agents" and "hyperhidrosis," as well as the textwords "antidepressant," "sweating," "hyperhidrosis," and "glycopyrrolate." References of articles found were searched as well. No report of the use of glycopyrrolate to treat antidepressant-associated excessive sweating was found and thus this is the first published report of this use.

Given that antidepressant-associated excessive sweating is relatively common and is associated with persistent suffering and impairment, clinicians should routinely screen for it and consider treating it. Glycopyrrolate may be an option and assessment of its efficacy in clinical trials is warranted.

\section{AUTHOR DISCLOSURE INFORMATION} interest.

The author declares no conflicts of 